Faculdade de Ciências Econômicas UFRGS

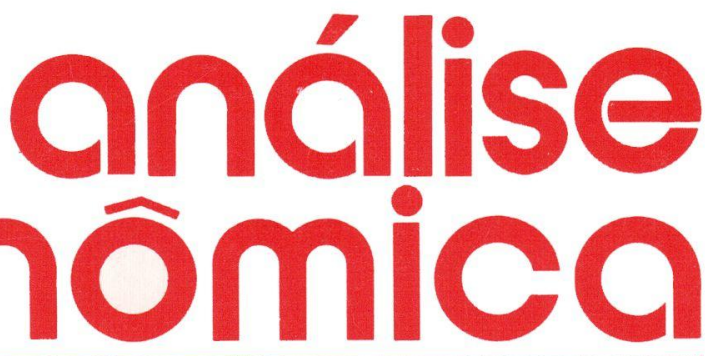

- COMÉRCIO INTERNACIONAL: UMA AGENDA DE PESQUISAS Carlos Alberto Primo Braga

- INFLACÃO E REFORMA MONETÁRIA: KEYNES E MISES Francisco Anuatti

- A ECONOMIA COMO CIÉNCIA Eleutério F.S. Prado

- REAVAlIAÇ̃̃o das PRIVATIZAÇÕES EM PAÍSES EUROPEUS

Márcio Wohlers de Almeida

- INTEGRAÇÃo BRASIL-ARGENTINA E A PRODUÇÃO DE GRÃOS José Eduardo Gutiérrez Perez Walter José Stülp

- SUBSTITUIÇÃO DE COLONOS POR TRABALHADORES ASSALARIADOS

Carlos José Caetano Bacha

- EQUILÍBRIO DISTRIBUTIVO EM MODELOS KALDORIANOS AMPLIADOS Joanílio Rodolpho Teixeira Jorge Thompson Araújo

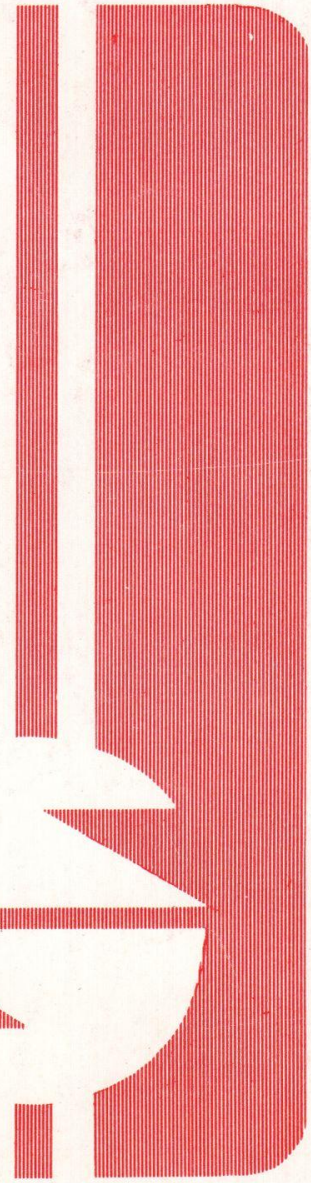


UNIVERSIDADE FEDERAL DO RIO GRANDE DO SUL.

Reitor: Prof. Tuiskon Dick

FACULDADE DE CIËNCIAS ECONÔMICAS

Diretor. Prof. Walter Meucci Nique

CENTRO DE ESTUDOS E PESQUISAS ECONÔMICAS

Diretor. Prof. Reinaldo Ignacio Adams

DEPARTAMENTO DE CIÊNCIAS ECONÔMICAS

Chefe: Prof. Pedro Cezar Dutra Fonseca

CURSO DE PÓS-GRADUAÇĀO EM ECONOMIA

Coordenador. Prof. Roberto Camps Moraes

CURSO DE PÓS-GRADUAÇĀO EM ECONOMIA RURAL

Coordenador. Prot. Aray Miguel Feldens

CONSELHO EDITORIAL:

Achyles Barcelos da Costa, Aray Miguel Feldens, Atos Freitas Grawunder, Carlos Augusto Crusius, Emani Hickmann, João Rogério Sanson, Juvir Luiz Mattuella, Maria Imilda da Costa e Silva; Nali de Jesus de Souza, Nuno Renan Lopes de Figueiredo Pinto, Ot́lia Beatriz Kroeff Carrion, Otto Guilherme Konzen, Paulo Alexandre Spohr, Pedro Cezar Dutra Fonseca, Reinaldo Ignacio Adams, Roberto Camps Moraes, Valter José Stülp, Yeda Rorato Crusius, Edgar Augusto Lanzer (UFSC) e Humberto Vendelino Richeter (UnB)

COMISSĀO EDITORIAL: Atos Freitas Grawunder, Pedro Cezar Dutra Fonseca, Reinaldo Ignacio Adams e Roberto Camps Moraes.

EDITOR: Nali de Jesus de Souza

SECRETARIA: Francisco Carlos Becco dos Santos, Maria Ivone de Mello (normalização), Vanete Ricacheski (revisão de textos), Wagner Nunes e Zélide Bregalda.

FUNDADOR: Prof. Antônio Carlos Santos Rosa

A Revista ANÁLISE ECONÔMICA publica dois números anuais nos meses de março e novembro. O preço da assinatura, para 1990, é de 7,0 BTNs (o número avulso custa 4 BTNs), a ser pago através de cheque nominal em nome da "Faculdade de Ciências Econômicas/ UFRGS". Aceita-se permuta com revistas congêneres. Aceitam-se, também, livros para elaboração de resenhas ou recensōes.

Toda correspondência, material para publicação, assinaturas e permutas devem ser dirigidos ao seguinte destinatário:

PROF. NALI DE JESUS DE SOUZA

Revista Análise Econômica

Av. João Pessoa, 52 - sala 28

90.040 - PORTO ALEGRE (RS) - BRASIL

Telefone: 25-5844 ramal 34 


\section{COMÉRCIO INTERNACIONAL: \\ UMA AGENDA DE PESQUISAS \\ PARA OS ANOS 90}

Carlos Alberto Primo Braga?

\section{INTRODUÇÃO}

A elaboração de agendas de pesquisa acadêmica é uma "indústria" quase que imune aos ciclos de expansão e de crise, que caracterizam as ciências sociais. Em tempos de crise, estas agendas se tornam úteis na medida em que identificam linhas de pesquisa que, eventualmente, levarão a novos paradigmas teóricos. Em fases de expansão, elas ajudam a mapear as fronteiras do conhecimento e a escolher as abordagens mais produtivas no contexto de um paradigma dominante. No caso da teoria do comércio internacional, a utilidade de um artigo como este - sem mencionar as razōes "corporativistas" que me levam a ter um interesse direto na multiplicação de pesquisas nesta área - pode ser racionalizada sob qualquer um destes enfoques. A teoria clássica do comércio internacional, por exemplo, encontra-se na defensiva. Aspectos da realidade internacional - tais como o sucesso do modelo intervencionista de política comercial no Japão - e desenvolvimentos té́ricos - por exemplo, a evolução da teoria não-competitiva do comércio internacional - compöem um quadro de crise do pensamento ortodoxo nesta área. Ao mesmo tempo, novas áreas de pesquisa - e.g., o comércio internacional de serviços e de tecnologia - apresentam uma vitalidade marcante mesmo quando desenvolvidas nos limites do paradigma clássico.

1 Professor do Departamento de Economia da FEAUUSP e pesquisador da FIPE. Este trabalho foi inicialmente apresentado no XVII Encontro Nacional de Economia, da ANPEC, realizado em Fortaleza, Ceará, em dezembro de 1989.
ANÁLISE ECONÔMICA
ANO $7 \quad$ № 12
NOVEMBRO/89
p.3-21 
Este artigo não tem a pretensão de cobrir as múltiplas questões suscitadas pelas novas teorias de comércio internacional ou pela aplicação de prinópios clássicos a novas áreas de estudo. A existência de uma extensa coleção de artigos recentes sobre estes temas desestimulam um esforço neste sentido. $O$ leitor interessado pode consultar as revisões elaboradas por Krugman (1987a; 1987b), Helpman (1984; 1989) e os recentes livros de Helpman e Krugman (1985; 1989) no que tange à evolução da teoria não-competitiva do comércio internacional. ${ }^{2}$ Cheng (1984) e Lyons (1987), por sua vez, sumariam a literatura relevante sobre o comércio internacional de tecnologia, enquanto Stern (1987), Gadbaw e Richards (1988) e Primo Braga (1989a) analisam as implicaçōes do debate sobre propriedade intelectual para o comércio internacional. Hindley e Smith (1984), Dias (1987), Feketekuty (1988), Gonçalves (1988a) e Gibbs (1989), por sua vez, são alguns dos autores que discutem a aplicação da teoria das vantagens comparativas ao comércio internacional de serviços.

O propósito aqui é o de simplesmente abordar alguns destes temas, tomando-como elo de união o protecionismo no contexto de políticas comerciais modernas. A seçäo ll explora o fenômeno do "novo protecionismo", adotando como tese a importância de falhas no sistema monetário internacional e no sistema multilateral de comércio para a onda protecionista no Primeiro Mundo. A seção III discute as reações dos paises em desenvolvimento frente ao "novo protecionismo" e analisa o confronto entre o "pessimismo exportador" associado a estas novas formas de protecionismo e o crescente interesse por polfticas de liberalização comercial no Terceiro Mundo. A seção IV sumaria algumas das contribuiçōes da teoria não-competitiva do comércio intemacional, que vêm sendo utilizadas como novos argumentos para medidas protecionistas. $O$ artigo se encerra com uma breve discussão da relevância dos temas de pesquisa aqui identificados para o Brasil.

\section{PROTECIONISMO E FALHAS "SISTÊMICAS"}

Desde meados da década passada, o mundo vem convivendo com um novo surto protecionista. A essência do "novo protecionismo" é a

2 Para as pessoas interessadas na teoria clássica do comércio internacional Jones e Neary (1984) e Corden (1984) oferecem excelentes revisరos de literatura. 
sua ênfase em barreiras não-tarifárias (BTNs). ${ }^{3}$ No período 1981-86, por exemplo, o Banco Mundial (1987: 142) estima que a incidência de BTNs sobre as importações dos países industrializados evoluiu de 13 para $16 \%$ do valor das mesmas no caso do comércio Norte-Norte, e de 19 para $21 \%$ no caso do comércio Norte-Sul. Sampson (1988: 136), por sua vez, estima que o grau de cobertura de BTNs em um grupo representativo de naçōes industrializadas cresceu de 19,6 para $22,7 \%$ no mesmo perlodo (excluindo o comércio de combustíveis). ${ }^{4}$

$\dot{E}$ bem verdade que estes indicadores não oferecem uma visāo nltida da trajetória do grau de restrição imposto aos fluxos do comércio internacional. E embora a taxa de crescimento do volume de exportações mundiais tenha sido em média de apenas $3 \%$ ao ano no período 1980-87 - em contraste com 5\% ao ano no perilodo $1970-80$ e $8,5 \%$ ao ano no período 1960-70 (GATT, 1988: 3) - é difícil estabelecer o papel exato do "novo protecionismo" na desaceleração do comércio internacional. Esta desaceleração parece ter sido mais um fruto da recessão mundial do ińlcio dos anos 80 do que de restriçōes ao comércio. Além do mais, o volume do comércio internacional voltou a crescer a um ritmo significativo em $1987(5 \%)$ e em 1988 (8,5\%), consolidando uma trajetoria de taxas crescentes que já se sustenta por quatro anos (GATT, 1989: 3). A despeito de todas estas qualificaçōes, vários analistas concordam com a proposição de que o sistema neoliberal de comércio, respaldado pelos prinaĺpios do GATT, nunca esteve tão ameaçado quanto nestes últimos anos. 5 Estas ameaças não se resumem ao "novo protecionismo", elas também surgem no contexto do "novo minilateralismo", um tema que foge aos limites deste artigo. ${ }^{6}$

As causas das crescentes pressões protecionistas a nivel mundial são várias.? Mas, sem dúvida, os desequilíbrios macroeconômicos dos paises industrializados - particularmente, os dos EUA - têm um papel de destaque neste processo. A trajetória ascendente destes desequilłbrios, por sua vez, remonta à ruptura do sistema de Bretton Woods em

3 Para detalhes adicionais sobre o "novo protecionismo" veja Nelson (1981).

4 Sampson (1988) usa dados da UNCTAD cobrindo as importaçóes feitas pela Áustria, Canadá, CEE (10), Finlândia, Japăo, Nova Zelândia, Noruega, Sulça e os Estados Unidos.

5 Veja, por exemplo, Leutwiler etal. (1985) e Martone e Primo Braga (1988).

6 Ao leitor interessado no tema do "novo minilateralismo" recomendo a coletânea organizada por Schott (1989). Veja também Primo Braga (1989b).

7 Para análises mais detalhadas sobre este tema veja, por exemplo, Salvatore (1987) e Bhagwati (1989). 
1971. Desde então, a economia mundial vem convivendo com uma espécie de "não-sistema" macroeconômico internacional (Corden, 1986: Capltulo 12). A proliferação de diferentes regimes cambiais e a crescente mobilidade internacional de capitais contribuiram para a erosão das disciplinas que o sistema deveria impor aos seus participantes.

Alguns exemplos da conexão "falha sistêmica/pressōes protecionistas" são os seguintes: a) em um mundo de taxas cambiais flexiveis, cada participante tem grande discreção na escolha de sua combinação de polfticas fiscal e monetária. Uma alternativa para os EUA, como nação emissora da moeda base da economia mundial, é a de adotar uma polf́tica de negligência benigna com relação ao valor do dólar, viabilizando o equilíbrio do sistema. Em tal cenário, que prevaleceu no início dos anos 80, a influência dos EUA sobre o valor do dólar ocorre por vias indiretas através de suas politicas monetária e fiscal. A taxa de juros se toma o instrumento central de uma política de ajuste do balanço de pagamentos, tendo a sua influência magnificada pela crescente integração dos mercados financeiros internacionais. $O$ "choque de juros" que teve um papel importante no desencadeamento da crise da dívida externa no Terceiro Mundo, por exemplo, foi um reflexo direto da combinação expansão fiscal com restrição monetária, que marcou os primeiros anos da Era Reagan. Como conseqüência deste 'mix' macroeconômico, o dólar experimentou uma forte sobrevalorização. As pressōes competitivas dal resultantes sobre o setor de bens comercializáveis da economia norte-ämericana estariam, portanto, por trás do aumento na demanda por proteçāo verificado neste período nos EUA. Estratégias agressivas de exportação adotadas por vários palses em desenvolvimento, em resposta à crise da divida, teriam contribuído para exacerbar ainda mais a demanda por proteçāo nos Estados Unidos; b) uma forma alternativa de apresentar a conexão acima mencionada se baseia na idéia do efeito "catraca", sugerido por Bergsten e Williamson (1983). A instabilidade das taxas reais de câmbio, uma marca da era pós-Bretton Woods, teria introduzido um viés protecionista na economia mundial. Fases de sobrevalorização da moeda doméstica se traduzem em aumentos na demanda por proteção e, eventualmente, em um aumento dos niveis de proteção. Existe, porém, uma assimetria neste processo (o efeito catraca) na medida em que em períodos de desvalorização real da moeda, a economia política do processo não favorece a desmontagem das barreiras protecionistas criadas nas fases de sobrevalorização.

É interessante observar, como Dornbusch e Frankel (1987) o fazem, que a discussão em torno do vínculo entre regimes cambiais e 
pressōes protecionistas parece ter tomado um rumo completamente distinto daquele que o debate sobre regimes cambiais no final dos anos 60 sugeria. Afinal de contas, em seu artigo clássico a favor de taxas de câmbio flexiveis, Johnson (1971) argumentava que a adoção deste regime favoreceria a expansão do liberalismo comercial. Com o câmbio totalmente livre o balanço de pagamentos equilibrar-se-ia automaticamente. A ausência de pressōes sobre as reservas internacionais dos palses sob este regime tenderia a eliminar uma das causas mais comuns por trás dá adoção de medidas protecionistas: episódios de crise cambial. Analogamente, os defensores de taxas de câmbio flexiveis acreditavam que sob este regime seria mais fácil evitar situaçōes de sobrevalorização da moeda do que sob taxas de câmbio fixas. A chave para a compreensão deste aparente conflito entre as proposições tebricas de Johnson e as defendidas por Bergsten e Williamson, por exemplo, está diretamente relacionada com a questāo do sistema econômico internacional subjacenie à análise de cada um destes autores. Enquanto Johnson construla o seu argumento com base em um mundo de pequena mobilidade de capitais onde os ajustes a variaçōes na taxa de câmbio se processavam a nível da conta de transaçōes correntes, as análises mais modernas refletem um mundo caracterizado por uma grande mobilidade de capitais, onde as transações a nível da conta de capitais são predominantes.

Um outro tipo de falha sistêmica, que contribuiu para a evolução do "novo protecionismo", foi o crescente descrédito do GATT. Muito embora o nivel de adesão ao Acordo Geral tenha continuado a crescer ao longo de todo este periodo, a parcela do comércio internacional conduzido dentro das disciplinas do GATT começou a diminuir a partir dos anos 70 . Além dos tradicionais problemas no comércio de produtos agricolas e têxieis, vários palses industrializados passaram a adotar BTNs de caráter discriminatório como uma forma de controlar o acesso aos seus mercados. Acordos de limitação voluntária das exportaçāes (VRA's - Voluntary Restraint Agreements), por exemplo, tornaram-se uma forma comum de proteção às indristrias "maduras" (e.g., siderurgia e indústria automobilistica) em certos países do Primeiro Mundo. Tais acordos são negociados politicamente e tendem a criar uma cumplicidade entre as partes envolvidas na medida em que o país (ou firma exportadora) apenado pode participar nos "lucros extras" gerados pela proteção. Além disso, dado que estas barreiras são o fruto de uma "negociação" entre 
as partes envolvidas, a probabilidade de um protesto frente ao GATT se reduz. ${ }^{8}$

A proliferação destas medidas de "área cinzenta" alimentou dúvidas a respeito da eficácia do GATT frente ao "novo protecionismo" mesmo porque a ilegalidade das mesmas do ponto de vista do Acordo Geral é uma questão em aberto. A crise do sistema multilateral de comércio se agravou ainda mais pelas crescentes distorções observadas na utilização de medidas de controle de comércio autorizadas pelo GATT.' Medidas 'anti-dumping' e anti-subsídio, por exemplo, ainda que consistentes com o GATT (Finger e Murray, 1989: 24), passaram a ser utilizadas com uma freqüência inusitada nos anos 80 . Vários analistas (Finger e Nogués, 1987; Bhagwati, 1989) têm interpretado tal desenvolvimento como um sinal de que políticas desenhadas para garantir práticas comerciais justas (o conceito de fair trade) teriam sido capturadas por interesses protecionistas. Neste contexto, as mesmas passaram a ser utilizadas como instrumentos de pressão sobre parceiros comerciais mais dinâmicos, levando-os a aceitar uma crescente regulação dos fluxos comerciais.

Mas talvez o fenômeno mais prejudicial ao GATT tenha sido o crescente sentimento de frustração entre as partes contratantes no que tange à capacidade do Acordo Geral em atender as principais preocupaçäes de seus participantes. ${ }^{10}$ Para os países em desenvolvimento esta frustração refletia a consciência das limitações da tese de um tratamento especial e diferenciado para os mesmos no contexto do GATT. ${ }^{11}$ Além disso, a cobertura deficiente oferecida pelo GATT em áreas de comércio de grande interesse para o Terceiro Mundo (agricultura e têxteis) e a Isua ineficácia frente ao "novo protecionismo" contribuiram para magnificar a frustração em tela. Entre os países desenvolvidos, as reclamações podiam ser organizadas em duas categorias básicas: aquelas referentes às dificuldades do sistema em garantir uma participação responsável de todas as partes contratantes e aquelas que enfocavam a cobertura ina-

8. Para detalhes a este respeito veja Hindley (1987a).

9 Neste artigo, o sistema multilateral de comércio é identificado com o próprio GATT. Como bem observa Jackson (1987), é possfivel imaginar-se um sistema multilateral independente do GATT como instituiçăo. No presente contexto, no entanto, tal simplificaçăo năo causa maiores problemas.

10 A este respeito veja, por exemplo, Martone e Primo Braga (1988) e Whalley (1988).

11 Sobre a questăo do tratamento especial e diferenciado para palses em desenvolvimento veja Hindley (1987b) e Wolf (1987). 
dequada do GATT no que tange aos "novos temas" de comércio internacional. A primeira categoria, baseada na denúncia dos efeitos "carona" (a possibilidade que urn pals tem de se beneficiar de concessões comerciais negociadas entre outras partes contratantes sem nada oferecer em troca graças à cláusula da nação-mais-favorecida) e "comboio" (o comportamento estratégico das partes contratantes em uma negociação multilateral tende a limitar a velocidade dos avanços nas negociações àquela adotada pelos participantes mais refratários a um processo de liberalização), contribuiu para estimular ainda mais o interesse pelo minilateralismo.12 A segunda categoria de reclamações alimentou os esforços de "reforma" do GATT, liderados pelos Estados Unidos, no sentido da incorporação do comércio de serviços, propriedade intelectual e de medidas de controle de investimentos no contexto de uma nova rodada de negociações multilaterais. Tais esforços culminaram com o lançamento da Rodada Uruguai em setembro de 1986.

Em termos de uma agenda de pesquisas, as questōes abordadas nesta seção sugerem os seguintes temas: a) é possível conter o "novo protecionismo" sem uma recauchutagem do sistema monetário internacional e do sistema multilateral de comércio?; b) quais as características ideais e quais as características viáveis destes novos sistemas?; c) inevitável a escolha entre taxas de câmbio administradas (e/ou coordenação macroeconômica) ou comércio internacional regulado?; d) podem (e devem) as regras do GATT ser estendidas aos "novos temas" de comércio internacional?

\section{O RETORNO DO PESSIMISMO EXPORTADOR}

Uma das conseqüências do "novo protecionismo" foi o ressurgimento do pessimismo exportador no Terceiro Mundo. Bhagwati (1986) observa que a primeira onda de pessimismo exportador foi desencadeada pelas teses de Prebisch (a proposição de que os termos de troca relevantes para países exportadores de produtos primários eram secularmente declinantes) e Nurkse (a tese de que a capacidade de absorção de importaçōes pelos pa'ses desenvolvidos imporia limitaçōes à utilização do comércio exterior como motor de crescimento para os palses do Terceiro Mundo). O ocaso destas teorias usualmente associado ao

12 Para maiores detalhes veja Wonnacot e Lutz (1989). 
efeito demonstração do dinamismo do comércio exterior nas primeiras duas décadas do pós-guerra e do desempenho superior das economias que seguiram o modelo de "promoção de exportações" (PE) em contraste com aquelas que seguiram o modelo "substitutivo de importações" (SI). ${ }^{13}$

Cabem aqui algumas breves observaçōes sobre o que estou caracterizando como modelo SI e modelo PE. Seguindo a abordagem proposta por Bhagwati $(1978 ; 1986)$, uma economia que segue o modelo SI se caracteriza por apresentar uma taxa de câmbio efetiva para as importaçōes superior àquela relevante para as exportaçōes. No caso dos palses da América Latina, por exemplo, o modelo SI começou a ser adotado de uma forma explícita na segunda metade dos anos 50 . Por intermédio de medidas protecionistas estas economias procuraram estimular o processo de industrialização, aumentando a rentabilidade relativa de atividades SI 'vis-à-vis' atividades exportadoras (tipicamente, atividades do setor primário). Como conseqüência, estas economias se afastaram da posição de equilíbrio de livre-comércio (de um ponto de vista alocativo) e passaram a conviver com um significativo viés antiexportador. ${ }^{14} \mathrm{O}$ modelo PE, por sua vez, caracteriza aqueles paises que - ou por permanecerem fiéis ao livre-comércio (e.g.; Hong-Kong) ou por adctarem medidas capazes de equilibrar o viés antiexportador após um período SI (e.g., Coréia do Sul) foram capazes de manter uma política comercial relativamente neutra, caracterizada pela igualdade das taxas de câmbio efetivas para exportações e importaçōes. Em sintese, o modeio PE (a despeito do seu nome) não advoga a introdução de um viés pró-exportador na economia. Ele, tampouco, é sinônimo de uma estratégia de laissez-faire.

A lógica do novo pessimismo exportador poderia ser apresentada da seguinte forma: ainda que se reconheça a superioridade do modelo PE 'vis-à-vis' o modelo SI, preciso levar em conta que a sua viabilidade depende de condiçōes favoráveis de acesso ao mercado internacional. Dado o crescente protecionismo observado nas naçōes industrializadas, a reorientação de estratégias de desenvolvimento no Terceiro Mundo no sentido do modelo PE seria ineficiente. Em outras palavras, a experiência dos palses de industrialização recente do Sudeste Asiático

\footnotetext{
13 Para visరos altemativas sobre as experiencias destes palses veja Lal e Rajapatirana (1987) e Singer (1988).

14 Para uma descriçăo detalhada deste processo veja Baiassa et.al. (1986).
} 
não poderia ser repetida em larga escala, dada a aparição do "novo protecionismo". Esta tese não depende de hipóteses pessimistas sobre a capacidade de absorção pelas economias desenvolvidas das exportaçöes dos palses em desenvolvimento. ${ }^{15}$ Ela simplesmente se baseia na hipótese de que crescentes exportações do Terceiro Mundo gerariam pressões adicionais a favor do protecionismo no Primeiro Mundo. Neste contexto, palses que reorientassem as suas estratégias comerciais no sentido do modelo PE poderiam ter uma surpresa desagradável.

O impacto final do "novo protecionismo", no entanto, é ainda uma questão em aberto. Como observado na seção Il, o comércio internacional e, em particular, as exportações dos paises em desenvolvimento voltaram a crescer significativamente nestes últimos anos. Os únicos palses a experimentar taxas negativas de crescimento anual médio de suas exportaçōes no perlodo 1982-87 foram os exportadores de petróleo (GATT, 1988: 21). Já os palses de industrialização recente que seguem - modelo PE foram capazes de continuar a expandir as suas exportações a taxas médias anuais significativas no perilodo em questão. Taiwan (19,2\%), Hong Kong (18,2\%), Coréia do Sul (16,7\%), e Cingapura $(6,7 \%)$ fornecem os exemplos mais óbvios neste contexto. Alguns autores, como Baldwin (1985), têm sugerido que o "novo protecionismo" não é tão "feio" quanto aparenta ser à primeira vista. Na realidade, existiriam muitas formas de burlar as restriçōes quantitativas no Primeiro Mundo e aqueles paises que adotam uma política comercial eficiente têm sido capazes de vencer tais restriçōes sem maiores problemas. A tese da "porosidade" do "novo protecionismo" é desenvolvida em detalhe por Bhagwati (1986: 30-33).

Não obstante tais considerações, é indiscutível que o "novo protecionismo" (ou a questão de acesso a mercados do Primeiro Mundo) figura entre as preocupações centrais dos países em desenvolvimento. A influência real do novo pessimismo exportador, porém, parece ter sido marginal até este momento. Na realidade, o que tem se identificado \& uma tendência liberalizante (aqui entendida como um movimento do modelo SI para o modelo PE) nas politicas comerciais do Terceiro Mundo (Primo Braga, 1989b; Whalley, 1989). Na América Latina, por exemṕlo, as primeiras reaçöes à crise da divida externa tenderam a privilegiar a maximização de superávits na balança comercial, independentemente dos custos envolvidos. $\grave{A}$ medida que estas pollticas comerciais se tor-

15. Veja, por exemplo, Cline (1982). 
naram mais discricionárias e complexas, os seus custos - em termos de ineficiência, corrupção e atritos com parceiros comerciais - aumentaram significativamente. Ao mesmo tempo, a utilização de subsídios à exportação para atenuar o viés antiexportador destas economias se tornou cada vez mais difícil dado o caráter pré-falimentar de vários governos da região. Em tal cenário, políticas de liberalização comercial passaram a ter um novo apelo.

Existem naturalmente várias outras razōes por trás desta "onda" liberalizante no Terceiro Mundo. O efeito demonstração do sucesso econômico dos países que seguiram o modelo $\mathrm{PE}$, as condicionalidades impostas por organismos multilaterais (FMl, Banco Mundial), o efeito renda associado à rápida recuperação das economias da OCDE após a recessão do início dos anos 80 , e pode-se até mesmo especular que o exemplo da crise das economias socialistas (caracterizadas por um viés anticomércio internacional) também vem contribuindo para este processo. Além disso, é importante assinalar que estas experiências recentes de liberalização diferem significativamente quanto à sua velocidade de implementação, abrangência e impacto. Tímidas em alguns casos, parecem mais refletir uma insatisfação com o status quo do quie uma reorientação do modelo de desenvolvimento (e.g., Brasil). Profundas, em outros casos, configuram uma ruptura com o passado, por vezes, estimulada por transformações políticas radicais (e.g., Chile), por vezes, refletindo a prevalência de um gradualismo ideológico liberalizante (e.g., México) e, em outros casos, gerada por situações de caos macroeconômico (e.g., Bollvia). ${ }^{16}$

A agenda de pesquisas que emerge das considerações apresentadas nesta seção extrapola as preocupaçōes da economia pura do comércio internacional, apontando também na direção da economia política do protecionismo. Alguns dos temas naturais seriam: a) admitindo-se a continuidade da montante protecionista no Primeiro Mundo (nos moldes do "novo protecionismo"), passará esta nova versão de pessimismo exportador a influenciar mais diretamente as polfticas comerciais do Terceiro Mundo?; b) quais dos movimentos de liberalização comercial ora em curso terão fôlego para adentrar os anos 90 de uma forma sustentada? Em outras palavras, que economias farão a transição bem-sucedida do modelo SI para o modelo PE?; c) faz sentido econômico um

16 O caso da Argentina, embora ainda muito recente para permitir uma avaliaçăo mais definitiva, parece se enquadrar nesta última categoria. 
movimento de liberalização comercial parcial? Afinal de contas, o argumento de que o modelo PE superior ao modelo SI não significa que um processo marginal de liberalização, em uma economia marcada por grandes distorções, seja eficiente.

\section{POLUTICAS ESTRATÉGICAS DE COMÉRCIO INTERNACIONAL}

A teoria não-competitiva do comércio internacional tem também contribuido para uma retomada da discussão dos possiveis benefícios de políticas intervencionistas. Em um mundo onde lucros extraordinấrios (rents podem ocorrer, a possibilidade de capturar tais lucros oferece - à primeira vista - uma fundamentaçāo alternativa para o ativismo governamental. ${ }^{17} \dot{E}$ importante reconhecer que os governos preferem maximizar o bem-estar dos seus cidadãos do que o bem-estar mundial. Como conseqüência a captura de setores dinâmicos, com lucros extraordinários, é um dos argumentos mais em voga dentre as justificativas correntes em prol de polfticas comerciais estratégicas.

Um bom exemplo neste contexto è o modelo desenvolvido em Spencer e Brander (1983), onde subsildios governamentais ou restriçōes às importaçōes podem transformar uma firma doméstica na empresa líder de uma determinada indústria a nivel internacional. A lógica subjacente a tal resultado advém do fato de que uma empresa isoladamente nem sempre pode convencer os seus competidores ex ante de sua disposição em dedicar os recursos necessários a sua transformação na empresa Ider do setor. O suporte governamental, neste caso, poderia dar à empresa doméstica a credibilidade para que o seu anúncio de investimentos (em $P \& D$, por exemplo) tenha um efeito dissuasório no que tange às estratégias de investimento dos seus competidores externos. Krugman (1987b: 135-36) utiliza um hipotético confronto entre a Boeing e a Airbus para ilustrar a operação do modelo em tela. Um subsídio europeu à Airbus poderia alterar a matriz de resultados associada à decisão estratégica destas empresas de se engajar ou não na produção de aviōes concorrentes. Em tal cenário, a produção do avião viria a ocorrer na Europa alijando a Boeing de um mercado que, por hipótese, so é capaz de acomodar um produtor com taxas de lucro positivas. Como conseqüência, a Airbus teria condições de capturar a totalidade dos

17 Para uma descriçăo dos argumentos tradicionais em favor do protecionismo veja Corden (1987). 
lucros extraordinários possiveis neste segmento de mercado. Não se levando em conta os eventuais custos para os consumidores, tal resultado ampliaria a renda nacional européia às custas dos EUA (Helpman e Krugman, 1989: 6).

Um argumento adicional a favor de polfticas intervencionistas pode ser desenvolvido com base em situações em que existem externalidades positivas. Atividades intensivas em conhecimento, por exemplo, costumam apresentar características que não são bem capturadas pelos modelos competitivos de comércio internacional. Investimentos em P \& D, a forma usual de se gerar conhecimento, são análogos a custos fixos na medida em que os seus resultados (um novo conhecimento) podem ser utilizados independentemente do número de usuários e/ou da escala de operação da atividade para a qual este insumo é relevante (Dasgupta e Stoneman, 1987: 3). A existência de economias de escala dinâmicas em indústrias intensivas em conhecimento é uma das principais razōes por trás das estruturas de mercado não-competitivas em que estas indústrias tipicamente operam. $E$ na medida em que é difícil garantir a perfeita apropriabilidade do conhecimento gerado, existe a presunção de que indústrias intensivas em $P$ \& $D$ gerem externalidades significativas. A utilização de políticas comerciais para estimular tais indústrias é, por conseguinte, racionalizada como uma estratégia voltada para a captura destas externalidades.

Não há dúvidas de que a teoria não-competitiva do comércio internacional vem abrindo novas avenidas para a pesquisa acadêmica. $\dot{E}$ importante reconhecer, no entanto, que os seus resultados não podem ser generalizados indiscriminadamente. Nada melhor neste ponto do que reproduzir as palavras de alerta de dois dos principais responsáveis pelo desenvolvimento da teoria em questão:

Meanwhile there are a number of reasons for treating trade policy conclusions cautiously. One is uncertainty: as we show, the effects of a given policy may depend crucially on the details of the market. Another is domestic political economy: there are many people eager to appropriate the results of new trade theories to support highly dubious political causes, and international economists do not want to be apologists for crude protectionism. Finally, there is the problem of international rivalry: a policy that benefits one country acting unilaterally may be hamful if everyone does it.

Helpman e Krugman (1989: 8-9)

Dixit (1987), por sua vez, oferece uma revisão bem-humorada dos vários problemas que marcam as recomendações de política derivadas 
dos modelos não-competitivos de comércio internacional. Em primeiro lugar, fica claro que o argumento a favor de intervenções desenhadas para estimular o desvio de lucros extraordinários requer, antes de mais nada, a identificação precisa daquelas indústrias onde tais lucros existem. Dixit (1987: 291) argumenta que o número destas indústrias é bastante reduzido. Muitas das indústrias que operam com lucros extraordinários são, na realidade, favorecidas por pclíticas comerciais protecionistas. Em outras palavras, estes lucros extraordinários refletem distorções geradas pờ intervençōes governamentais prévias. É evidente que em tais circunstâncias, uma política comercial orientada apenas pela captura de lucros extraordinários pode ser desastrosa.

Lucros extracrdinários podem eventualmente surgir no contexto de investimentos bem sucedidos em P \& D. A idéia de se proteger indústrias intensivas em $P \& D$ como uma forma de estimular tal possibilidade é, no entanto, bastante arriscada. Afinal de contas é possível que os lucros extraordinários das firmas cujos investimentos em $P$ \& D frutificaram sejam a imagem especular das perdas daquelas firmas cujos investimentos fracassaram. ${ }^{18}$ Várias outras qualificaçōes são pertinentes e tendern a diminuir o apelo da idéia de se usar políticas comerciais para a captura de lucros extraordinários. Competição doméstica (redefinindo a posição da função de reação do modelo Brander-Spencer de forma a tornar ambigua a intervenção ótima), a necessidade de se definir com grande precisão os segmentos a serem protegidos (dado que a promoção de largo espectro é ineficiente), a possibilidade de que os mercados relevantes sejam contestáveis (uma forma alternativa de se introduzir os problemas levantados por Dixit), e eventuais impactos perversos da polfțica de promoção a nível de equilíbrio geral são algumas destas outras qualificações discutidas na literatura. ${ }^{19}$

Polliticas dedicadas à promoção de setores com elevadas externalidades positivas também estão sujeitas a numerosas críticas. A questão empírica da mensuração destas externalidades, por exemplo, continua a desafiar os analistas. Além disso, a diferença entre externalidades de caráter nacional e aquelas que têm um carâter internacional contribuem para tornar ainda mais complexo o cálculo do impacto, em termos de bern-estar, de uma política intervencionista. Krugman (1987c: 195-96),

8 Veja Dixit (1987: 292) para uma discussáo desta possibilidade.

9 Veja, por exemplo, Krugmann (1987a; 1987b). 
por exemplo, argumenta que apenas aquelas atividades que geram externalidades de caráter nacional - i.e., externalidades cuja influência se limita às firmas domésticas - deveriam ser alvo de políticas estratégicas.

Os limites de uma política comercial estratégica ficam ainda mais claros quando a análise incorpora uma perspectiva de economia política. A possibilidade de medidas de retaliação e até mesmo de guerras comerciais, por exemplo, redefine dramaticamente as chances de se alcançar um ganho de bem-estar através de polfticas intervencionistas. Além disso, estas políticas são facilmente "capturadas" por interesses especiais que passam a administrar os esquemas de promoção às custas da sociedade como um todo. $\dot{E}$ por isto que muitos analistas costumam encerrar sudus avaliações sobre a teoria não-competitiva do comércio internacional, reconhecendo a sabedoria das recomendaçōes de política comercial extraídas da teoria ortodoxa. ${ }^{20}$

A agenda de pesquisas relevante neste caso pode ser definida de uma forma bastante simples. Cumpre explorar empiricamente os desenvolvimentos teóricos alcançados. A utilização da teoria dos jogos nestes modelos, por exemplo, abre uma verdadeira Caixa de Pandora no que tange à metodologia para testes empíricos. Outros pontos dignos de investigação incluem a análise dos aspectos políticos da implementação de políticas-comerciais estratégicas (e.g., que grupos se articulam para viabilizá-las?) e a evolução da interface política comercial/política industrial (e.g., é possível a adoção de uma política comercial estratégica na ausência de uma política industrial bem definida?). Cabe também pesquisar até que ponto estes desenvolvimentos teóricos terão repercussões no Terceiro Mundo, influenciando as políticas comerciais desta regiã̃o.

\section{CONSIDERAÇÕES FINAIS}

Os temas de pesquisa aqui identificados naturalmente refletem a minha própria agenda neste momento. A despeito deste viés, acredito que os mesmos cobrem algumas das indagações mais relevantes nesta área de conhecimento. Alguns outros temas a que me referi apenas

20 Veja, por exemplo, Dixit (1987: 302) e Krugmann (1987b: 142-43). 
brevemente - por exemplo, serviços, propriedade intelectual, minilateralismo - vêm também suscitando um amplo conjunto de pesquisas, teóricas e emplricas que, certamente, influenciarão o perfil da teoria do comércio internacional nos anos 90 .

Naturalmente, muitas das questōes discutidas acima podem ser abordadas a partir de uma perspectiva brasileira. A questão das falhas sistêmicas, por exemplo, provoca a seguinte indagação: Pode o Brasil ter uma influência positiva no processo de reorganização dos sistemas financeiro internacional e multilateral de comércio ${ }^{21} \mathrm{O}$ problema do "novo protecionismo", por sua vez, leva à questão da relevância do pessimismo exportador no que tange ao dinamismo e à composição das exportações brasileiras. ${ }^{22} \mathrm{Já}$ a "nova" teoria do comércio internacional, com sua ênfase em mercados não-competitivos, sugere o seguinte tema: Pode uma política consistente de liberalização comercial ser implementada em um país que adota um "arremedo" de polftica industrial intervencionista?

Mas o tema que acredito merecer urn esforço especial de pesquisa neste momento é o da questão da economia política da proteção no Brasil. Quais são os setores da sociedade beneficiados pela atual politica comercial brasileira? Como as demandas por proteção se articulam? Como o Estado reage a estas demandas? Quais os custos e beneficios, em termos de bem-estar, gerados pelo emaranhado de medidas protecionistas que tolhem a economia brasileira? A análise destas questōes se impõe como uma tarefa fundamental para o desenho de uma política comercial mais eficiente para o Brasil.

\section{BIBLIOGRAFIA}

BALASSA, Bela et alii. Toward Renewed Economic Growth in Latin America. Washington, D.C. Institute for International Economics, 1986.

BALDWIN, Robert. Ineffectiveness of Protection in Promoting Social Goals. The World Economy, June, 1985, p.109-18.

$2{ }^{1}$ A forma de negociação da divida externa e a agenda brasileira na Rodada Uruguai seriam os canais mais diretos para o exercício desta influência. Com relaçăo ao desenho de uma agenda "positiva" para o Brasil na Rodada Uruguai, veja Martone e Primo Braga (1988).

22 Sobre este tema, veja Gonçalves (1988b). 
BANCO Mundial. World Development Report 1987. New York, Oxford University Press, 1987.

BERGSTEN, C. Fred e MLLIAM R. Cline (eds.) Trade Policy in the 1980s. Washington, Institute for International Economics, 1983.

BERGSTEN, C. Fred e JOHN Williamson. Exchange Rates and Trade Policy. In: BERGSTEN, C.F. e CLINE, R.W. (eds). op.cit., 1983.

BHAGWATI, J. Foreign Trade Regimes and Economic Development Anatomy and Consequences of Exchange Control Regimes. Cambridge, Mass. Ballinger Publishing Co, 1978.

. Export Promoting Trade Strategy: Issues and Evidence. Washington, D.C. The World Bank, 1986. (Discussion Paper).

. The Rise of Protectionism, Economic Impact, 2ㅇ Trimestre, 1987, p.6-12.

CLINE, William. Can East Asian Model of Development be Generalized. World Development, Fev. 1982, p.81-90.

CHENG, L. International Trade and Technology: A Brief Survey of The Literature, Weltwistschaftliches Archiv, 120, 1984, p.165-89.

CORDEN, W. Max. The Normative Theory of International Trade. In: JONES, R.W. e KENEN, P.B. (eds.) Handbook of International Trade, 1984, Vol. I, cap. 2, p.73-130.

. Inflation Exchange Rates and The World Economy, Chicago, The University of Chicago Press, 1986.

. Protection and Liberalization: A Review of Analytical Issues, Washington, International Monetary Found - IMF (Occasional Paper, n.54).

DASGUPTA, P. e STONEMAN, P. (eds). Economic Policy and Technological Performance, Cambridge, Cambridge University Press, 1987.

DIAS, Vivianne V. Produção e comércio de Serviços: Notas Conceituais. Revista Brasileira de Comércio Exterior, 14 (nov/dez) 1987, p.2-13. DIXIT, A.K. Trade Policy: An Agenda for Research. In: KRUGHAN, P.R. (ed.), Strategic Trade Policy and The New International Economics, Cambridge, Mass. The MIT Press, p.283-304.

DORNBUSCH, R. e FRANKEL, J. Macroeconomics and Protection. In: 
STERN, R. (ed.) U.S. Trade Policies in a Changing World Economy, Cambridge, Mass., The MIT Press, 1987.

FEKETEKUTY, G. International Trade in Services: An Overview and Blueprint for Negotiations. Cambridge, Mass. Ballinger Publishing Co., 1988.

FINGER, J.M. e MURRAY, T. Policing Unfair Imports: The United States Example, Abril, mimeo, 1989.

. (1987) International Control of Subsidies and Countervailing

Duties, The World Bank Economic Review, Vol. 1, nº 4, set. 1987, p.707-726.

GADBAW, R.M. e RICHARDS, T.J. (eds.) Intellectual Property Rights Global Consensus, Global Conflict?, Boulder, Westview Press, 1988.

GATT. International Trade 87-88, Genebra, 1988. - Press Release, 21 de fevereiro, 1988.

GIBBS, Murray. Trade in Services: A Challenge for Developments. In: BRESSAND, A. e NICOLAIDIS, K. Strategic Trends in Services An Inquiry Into The Global Service Economy, New York, Harper \& Row, 1989.

GONÇALVES, R. Transaçōes Internacionais de Serviços do Brasil e Negociações Multilaterais. Rio de Janeiro, PNPE, mimeo, 1988a (Project Report).

. O Acesso das Exportações ao Mercado Externo e as Negociações Internacionais. São Paulo, FIPE, mimeo. (1986b).

HELPMAN, E. Increasing Returns, Imperfect Markets, and Trade Theory. In: JONES, R.W. e KENEN, P.B., op. cit., 1984, cap. 7, p.325-366.

. The Non-Cclmpetitive Theory of International Trade and Trade Policy, First Annual World Bank Conference on Development Economics, Washington, Abril 1989.

HELPMAN, E. e KRUGMAN, P.R. Market Structure and Foreign Trade, Cambridge, Mass. The MIT Press, 1985.

- Trade Policy and Market Structure, Cambridge, Mass. The MIT Press, 1989.

HINDLEY, B. GATT Safeguards and Voluntary Export Restraints: What 
are The Interests of Developing Countries?, The World Bank Economic Review, vol. 1, ñ 4, set. 1987a.

. Different and More Favorable Treatment - and Graduation, In: FINGER, J.M. e OLECHOWSKI, Andrej (eds.) The Uruguai Round: A Handbook on Multilateral Trade Negotiations, Washington, The World Bank, 1987b.

HINDLEY, B. e SMITH, A. Comparative Advantage and Trade in Services. The World Economy, 7, dez. 1984, p.369-89.

JACKSON, J.A. Multilateral and Bilateral Negotiating Approaches for the Conduct of U.S. Trade Policies. In: STERN, R.M., op. cit., 1987, p.377-401.

JOHNSON, H.G. The Case for Flexible Exchange Rates 1969. In: JOHNSON, Further Essays on Monetary Economics. Londres, Allen and Unwin, 1971.

JONES, R.W. e KENEN, P.B. Handbook of International Economics, vol. 1, Amsterdam, North-Holland, 1984.

JONES, R.W. e NEARY, J.P. The Positive Theory of International Trade, In: JONES, R.W e KENEN, P.B., op.cit., 1984, cap. 1, p.1-62.

KRUGMAN, P. Strategic Sectors and International Competition. In: STERN, R.M. op.cit., 1987a, p. 207-232. . Is Free Trade Passé? The Journal of Economic Perspectives, vol. 1, $\mathrm{n}^{2} 2,1987 \mathrm{~b}$, p.131-144.

. Technology - intensive goods. In: FINGER, J.M. e OLECHOWSKI, Andrej. op.cit., 1987c, p.191-197.

LAK, D. e RAJAPATIRANA, S. Foreign Trade Regimes and Economic Growth in Developing Countries. The World Bank Research Observer, vol. 2, $n=2,1987$, p. 189-218.

LEUTWLER, F. et al. Trade Policies for a Better Future: Proposals for Action. Genebra, GATT Independent Study Group, março, 1985.

LYONS, B. International Trade and Technology Policy. In: DASGUPTA, P. e STONEMAN, P., op. cit., 1987, p.169-205.

MARTONE, C.L. e PRIMO BRAGA, C.A. Brazil and The World Economy: Past Development and Current Problems. The Trade Policy Meeting, Rockeffeler Foundation, Bellagio, Itália, mimeo, 1987.

NELSON, Douglas R. The Political Structure of The New Protectio- 
nism, World Bank Staff Working Paper no 471, julho, 1981.

PRIMO BRAGA, C.A. The Economics of Intellectual Property Rights and

The GATT: A View From The South. Vanderbilt Journal of Transnational Law. vol. 22, n 2, 1984a, p.243-264.

. U.S. - Latin American Trade: Challenges for the 1990s,

Economic Impact, $n^{\circ}$ 67, 2 Trimestre, 1984b, p.51-55.

SALVATORE, D. The New Protectionism Threat to World Welfare; Introduction, In: SALVATORE, D. (ed.) The New Protectionism Threat to World Welfare, New York, North Holland, 1987, p.1-27.

SAMPSON, G.P. Developing Countries and The Liberalization of Trades in Services. In: WHALLEY, J. (ed.) Rules, Power and Credibility. vol. 1, London, Ontario, The University of Western Ontario, 1988, p.101-114.

SCHOTT, J.J. ed. Free Trade Areas and U.S. Trade Policy, Washington, Institute for International Economics, 1989.

SINGER, H.W. The World Development Report 1987 on the Blessings of Outward Orientation; A Necessary Correction, The Journal of Development Studies, 24, janeiro, 1988, p.232-236.

SPENCER, B.J. e BRANDER, J.A. International R \& D Rivarly and Industrial Strategy, Review of Economic Studies, nํ 50, 1983, p.707722.

STERN, Richard. Intellectual Property. In: FINGER, J.M. e OLECHOWSKI (eds.), op.cit., 1987, p.198-206.

STERN, Robert M. ed. U.S. Trade Policies in a Changing World Economy, Cambridge, Mass. The MIT University Press, 1987.

WONNACOTT, P. e LUTZ, M. Is There a Case for Free Trade Areas?, In: SCOTT, J.J., op.cit., 1989, p.59-84.

WHALLEY, John. (ed.) Rules, Power and Credibility, vol. 1, London, Ontario. The University of Western Ontario, 1988.

Recent Trade Liberalization in The Developing World: What is Behind it, and Where is it Headed?, maio, mimeo, 1989.

WOLF, M. Differential and More Favorable Treatment of Developing Countries and the International Trading System, The World Bank Economic Review, vol. 1, n 4, set. 1987, p.647-668. 